\title{
6. Acceleration of Development of Silkworm Ovary by Transplantation into Young Pupa.
}

\author{
By Soichi FukudA. \\ Sericultural Laboratory of Katakura Co., Matumoto. \\ (Comm. by N. YATSU, M.I.A., Jan. 12, 1939.)
}

In the silkworm, as is wellknown, the development of the ovary is very slow in the larval stage, but upon entering in the pupal stage the ovary undergoes a rapid growth and attains a completely mature state at the time of emergence of the moth.

In the summer of 1937 I found a remarkable acceleration of the development of the larval ovary transplanted into the young pupae. The results will be briefly dealt with in this paper.

Material and method. The ovaries of the larvae on the third day of the fifth instar of Japanese univoltine race were used as transplantats.

The transplantation was performed in the pupae of following four series of Chinese bivoltine race: (1) those bilaterally gonadectomized on the second day of the fourth instar, (2) bilaterally and (3) unilaterally gonadectomized at the time of transplantation and (4) the normal pupae. In order to know exact age of the pupae, the silkworms were taken out of the newly spun cocoons and left untouched until they pupate. Pupae younger than 15 hours alone were used for experimentation.

The transplantation was made in place of the right gonad in both bilaterally and unilaterally gonadectomized pupae and in the normal ones in the abdomen one or two segments anterior to the place where the gonads were situated. One ovary, about $2 \mathrm{~mm}$ in diameter (fig. $2 \mathrm{~b}$ ), was introduced into the fat-body from a small slit made on the dorsal skin.

As the controls some five hundred silkworms of the same race as the donors were used. In addition, transplantations of the ovaries of the larvae on the third day of the fifth instar into the other larvae of same age were made. In this series, one of the ovaries or testes of the host was always removed from a small slit made on the dorsal side of the gonadial segment and a donor's ovary was then inserted.

Results. The moths were dissected on the day of emergence. The transplanted ovaries were found in many cases (Table 1).

TABLE 1.

\begin{tabular}{c|c|c|c|c}
\hline HOST & SEX & $\begin{array}{c}\text { TRANSPLANTED } \\
\text { PUPAE }\end{array}$ & $\begin{array}{c}\text { EMERGED } \\
\text { MOTHS }\end{array}$ & $\begin{array}{c}\text { MOTHS WITH } \\
\text { TRANSPLANTED } \\
\text { OVARY }\end{array}$ \\
\hline $\begin{array}{c}\text { Bilaterally gonadecto- } \\
\text { mized on the second } \\
\text { day of the fourth } \\
\text { instar }\end{array}$ & $\circ$ & 31 & 24 & 20 \\
\hline
\end{tabular}




\begin{tabular}{|c|c|c|c|c|}
\hline HOST & SEX & $\begin{array}{c}\text { TRANSPLANTED } \\
\text { PUPAE }\end{array}$ & $\begin{array}{c}\text { EMERGED } \\
\text { MOTHS }\end{array}$ & $\begin{array}{l}\text { MOTHS WITH } \\
\text { TRANSPLANTED } \\
\text { OVARY }\end{array}$ \\
\hline $\begin{array}{l}\text { Bilaterally gonadecto- } \\
\text { mized simultaneously } \\
\text { with transplantation }\end{array}$ & क & $\begin{array}{r}19 \\
8\end{array}$ & $\begin{array}{r}10 \\
5\end{array}$ & $\begin{array}{r}10 \\
4\end{array}$ \\
\hline $\begin{array}{l}\text { Unilaterally gonadecto- } \\
\text { mized simultaneously } \\
\text { with transplantation }\end{array}$ & क & $\begin{array}{l}20 \\
22\end{array}$ & $\begin{array}{l}15 \\
13\end{array}$ & $\begin{array}{l}15 \\
13\end{array}$ \\
\hline Normal & $\begin{array}{l}\text { के } \\
\text { or }\end{array}$ & $\begin{array}{l}27 \\
24\end{array}$ & $\begin{array}{l}12 \\
20\end{array}$ & $\begin{array}{r}9 \\
17\end{array}$ \\
\hline
\end{tabular}

In every series, the degree of development of the transplanted ovary, especially the number of large oocytes, was different individually but no marked difference was recognized in the different kinds of the hosts.

The ovaries were alway found as a mass embedded in the fatbody. The ovarioles have increased in size and length, although they were generally far shorter than the ovarioles of the normal moths (fig. $1 \mathrm{a}, \mathrm{b}$ and fig. $2 \mathrm{a}$ ). In all cases the ovaries contained the oocytes almost as large as the mature eggs. Some of the fully grown occytes were yellowish in color being provided with the hardened chorion as in the mature eggs, while others were not yet enclosed by the hard shell. The number of these mature or nearly mature large oocytes was different in different individuals, ranging up to some fifty. Besides these large oocytes there were many immature oocytes at different stages of development.

It should especially be mentioned here that there was no remarkable difference whether the hosts were male or female and whether they were with or without gonad (fig. $1 \mathrm{a}, \mathrm{b}$ ).

The gonads of the host were

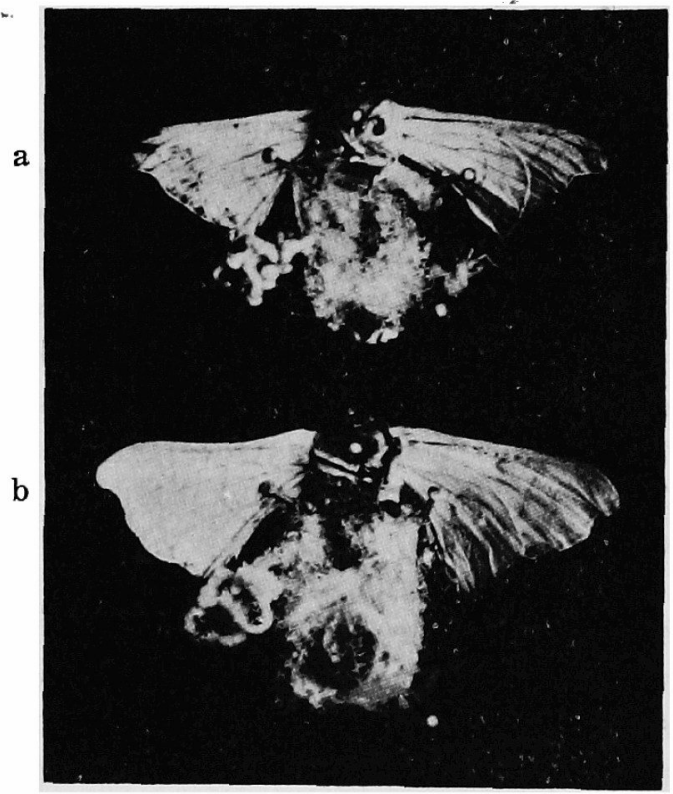

Fig. 1. Transplanted larval ovary in moth gonadectomized in larval stage. Note remarkable development.

a. male; b. female. Natural size. normal, apparently not being influenced by the transplanted ovary.

In every series of experiments the moths emerged from the operated pupae 9 to 11 days after pupation. Therefore the transplanted larval ovaries attained the above-mentioned state of development during this period. In the same interval the control larvae finished the active larval life and spun their cocoons. Some of them were kept alive until they transformed into the moths while others were killed on the days 
of emergence of the moths from the operated pupae. At that time most of control larvae had undergone pupation. The ovaries of these young pupae were of course small and did not contain any large oocytes (fig. $2 \mathrm{c}, \mathrm{d}$ ).

The larval ovaries transplanted in the fifth instar larvae did not show any acceleration in development. They grew gradually as the ovaries of normal worms. The moths emerged from the operated worms and their controls about 11 days after pupation."

Conclusion. From the above mentioned experiments it is obvious that the larval ovaries attain a rapid development if transplanted into the pupae of whichever sex, regardless the presence or absence of gonads. On the third day of the fifth instar the silkworm ovary already contains a number of oocytes which are able to complete the development and transform into mature eggs with

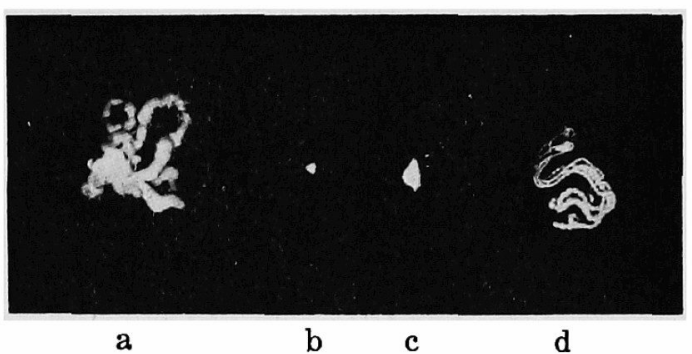

Fig. 2. Ovaries of experimentals and controls. Natural size.

a. Transplanted larval ovary taken out of male moth unilaterally gonadectomized.

b. Larval ovary at time of transplantation, that is, on third day of fifth instar.

c. Ovary of control at time of pupation.

d. Ovary of control about 3 days after pupation.

hard chorion in about ten days if external conditions are modified. The failure of the further development of these oocytes in the larval body may therefore be due not to the oocytes themselves but to the environmental condition in the body fluid of larvae.

1) The pupal period of the univoltine race employed in this experiment is generally one or two days longer than that of the bivoltine race. 